\title{
Palatal obturator prosthesis: case series
}

\author{
Prótese obturadora palatina: série de casos
}

\author{
Juliana Machado DOMINGUES ${ }^{1}$ \\ Gislene CORRÊA' \\ Romeu Belon FERNANDES FILHO' \\ Elaini Sickert HOSNI ${ }^{1}$
}

\begin{abstract}
Surgical treatment for palate cancers can result in oral-nasal/sinus communication, which impairs the swallowing, speech and chewing ability of patients with reflux of ingested food into the nasal cavity, reducing their quality of life. This article aims to report how three cancer patients, with different types of palate cancer undergoing partial maxillectomy with oroantral or oral-nasal communication as postoperative sequelae were prosthetically rehabilitated from 2009 to 2015. The prostheses were made by dental-surgeons interns in the service of the Multidisciplinary Residency in Oncological Healthcare of the Hospital School of the Federal University of Pelotas (HE/UFPel). One of the patients is completely edentulous, the second partially toothed and in the third case the patient is totally toothed, only requiring the obturator. The creation of prosthetic rehabilitation followed the steps of conventional prostheses, especially observing the particularities in the planning, molding, installation and adjustment stages of the prosthesis. In all cases there was improvement on speech immediately after the prosthesis installation and patients reported greater ease to feed.
\end{abstract}

Indexing terms: Complications. Dental occlusion. Head and neck neoplasms. Mouth neoplasms. Prosthodontics. Rehabilitation.

\section{RESUMO}

O tratamento cirúrgico para os cânceres de palato pode resultar em comunicação buco-nasal/sinusal, o que interfere negativamente na capacidade de deglutição, fonação e mastigação dos pacientes, com refluxo dos alimentos ingeridos para a cavidade nasal, reduzindo sua qualidade de vida. Neste artigo, objetiva-se relatar como foram reabilitados proteticamente, no período de 2011 a 2015 , três pacientes oncológicos com diferentes tipos de câncer de palato submetidos à maxilectomia parcial com comunicação buco-sinusal ou buco-nasal como sequela pós-operatória. As próteses foram confeccionadas por Cirurgiões-dentistas residentes no serviço de Residência Multiprofissional em Atenção à Saúde Oncológica do Hospital Escola da Universidade Federal de Pelotas (HE/UFPel). Um dos pacientes é edêntulo total, o segundo é dentado parcial e no terceiro caso a paciente é totalmente dentada, necessitando apenas do obturador. A confecção das próteses obturadoras seguiu as etapas das próteses convencionais, observadas particularidades principalmente nas fases de planejamento, moldagem e instalação e adaptação da prótese. Em todos os casos observou-se melhora na fala imediatamente à instalação da prótese e os pacientes relataram maior facilidade ao se alimentar.

Termos de indexação: Complicações. Oclusão dentária. Neoplasias de cabeça e pescoço. Neoplasias bucais. Prostodontia. Reabilitação.

\section{INTRODUCTION}

Treatment for cancers in the head and neck region commonly involves a surgical stage ${ }^{1}$. When the disease affects the maxilla, the surgical treatment (partial or total maxillectomy) often results in communications between the oral cavity and nasal/sinus cavities ${ }^{2-4}$. Patients with oro-nasal/sinus communication face several problems, including fluid reflux through nasal cavity as well as difficulty chewing, swallowing and speaking, with immediate reduction in the quality of life ${ }^{5-6}$. The literature brings no consensus on rehabilitation of patients undergoing maxillectomies. Rehabilitating these patients is a challenge and fulfilling the requirements such as retention, stability and sealing of the prosthesis can be hard $^{2-4}$. Rehabilitation of the patient with maxillary loss can comprise surgical or prosthetic treatment or even a combination of both. Due to the relatively easy follow-up

\footnotetext{
${ }^{1}$ Hospital Escola da Universidade Federal de Pelotas, Programa de Residência Multiprofissional em Atenção à Saúde Oncológica. Rua Prof. Dr. Araújo, 538, Centro, 96020-360, Pelotas, RS, Brasil. Correspondência para / Correspondence to: JM DOMINGUES. E-mail: <jmdomingues@outlook.com>.
} 
of those cancer patients with a high risk of relapse and because of low-costs, short treatment time, immediate esthetic and functional improvement relating to prosthetic rehab, some authors favor prosthetic rehabilitation (use of obturators, rehabilitation prosthesis, bulbs) over complex procedures, despite a lack of consensus on which would be the best approach, suggesting the need for longitudinal studies ${ }^{7}$. The purpose of this paper is to report how three cancer patients subjected to partial maxillectomy with oroantral or oral-nasal communication as a postoperative sequelae were prosthetically rehabilitated.

\section{CASE REPORT}

\section{Case 1}

Male, 70 years-old, former smoker (quit 4 years previously), with pulmonary emphysema and a diagnose of squamous cell carcinoma T4NOMO EC IV located in the transition area between the hard and soft palate to the right side, subjected to partial maxillectomy on 01/15/2011 and 29 sessions of radiotherapy with a total dose of 58 Gy. The patient presented to the Dental clinic of the Hospital School of the Federal University of Pelotas at the end of his radiotherapy sessions. On initial examination, he presented with radiodermatitis, pseudomembranous candidiasis and an area of necrotic bone exposed in the hard palate to the right immediately adjacent to the oronasal communication area, which was treated for 2 years and 5 months until full healing by second intention. In this period, the patient used a silicone obturator plate, which facilitated speech and feeding functions even in the absence of teeth (Figure 1). After achieving complete healing, an obturator upper full denture and a lower full denture were made (Figure 2). The steps for making the obturator prosthesis were not different from those for making a conventional total prosthesis, except some specific care in the prosthesis molding and fitting steps as described below. On the initial impression, a Vaselineembedded gauze was inserted into the palate cavity in order to prevent excess impression material extravasation into the nasal cavity; the impression tray was chosen according to the patient arch size and the impression was performed with alginate (Cavex ColorChange ${ }^{\circledR}$ ). The functional impression was performed using customized trays made from the study model, taking care to protect the communication area with a Vaseline-embedded gauze, always ensuring that the cavity edges were free from impression material; the peripheral seal was copied with low-fusion reversible hydrocolloid sticks (Exact Stick Godiva - Nova DFL ${ }^{\circledR}$ ) and the impression itself performed with polyether (Impregum Soft $\left.{ }^{\circledR}\right)$. The steps for registering the intermaxillary relationship as well as esthetic and functional tests demanded no particularity. On denture installation, it was observed that the obturator prosthesis had several retention areas in the obturator (due to slight impression material extravasation; if this design is copied in the prosthesis and not relieved at the finishing and polishing stages, it would form retentions), which were polished deown so that, at insertion, the prosthesis was not fixed at the communication area. The prosthesis was then ckecked to ensure it was not too heavy and the obturator was made hollow to make it lighter. The procedures occurred weekly. In the first return after installing the prosthesis, the patient reported that when swallowing, foods were nasally regurgitated; a complaint that was eradicated after adjustments to the prosthesis and obturator using polishing instruments. The patient is being monitored and has been satisfied with his prosthesis for 2 years and 2 months. The current aspect of the prosthesis can be seen in Figure 2 .

\section{Case 2}

Female patient, 47 years old, non-smoker, operated on 04/07/2009 for an adenoid cystic carcinoma on the right side of the hard palate. She was referred by the head and neck surgeon to the Dental Hospital clinic (HE/UFPel) for post-surgical rehabilitation. Various clinical procedures were necessary prior to the installation of the obturating removable partial prosthesis (RPP) (Figure 3). A provisional obturating RPP was prepared, which was installed in the second appointment, with immediate speech and swallowing improvement. The patient wore the provisional prosthesis until completion of the clinical procedures, when a definitive obturating prosthesis and lower RPP started to be made. The prosthesis making steps were similar to those for making a conventional RPP, observing the same peculiarities of the previous case (Figure 4). Oral hygiene motivation and periodontal treatment were constantly provided in the follow-up period. Now, 3 years and 6 months after installation, the patient is satisfied with the upper prosthesis, with a clear improvement of speech and swallowing. She did, however, in the last follow-up vist report difficulty sucking, for which relining the prosthesis resolved her complaint. 

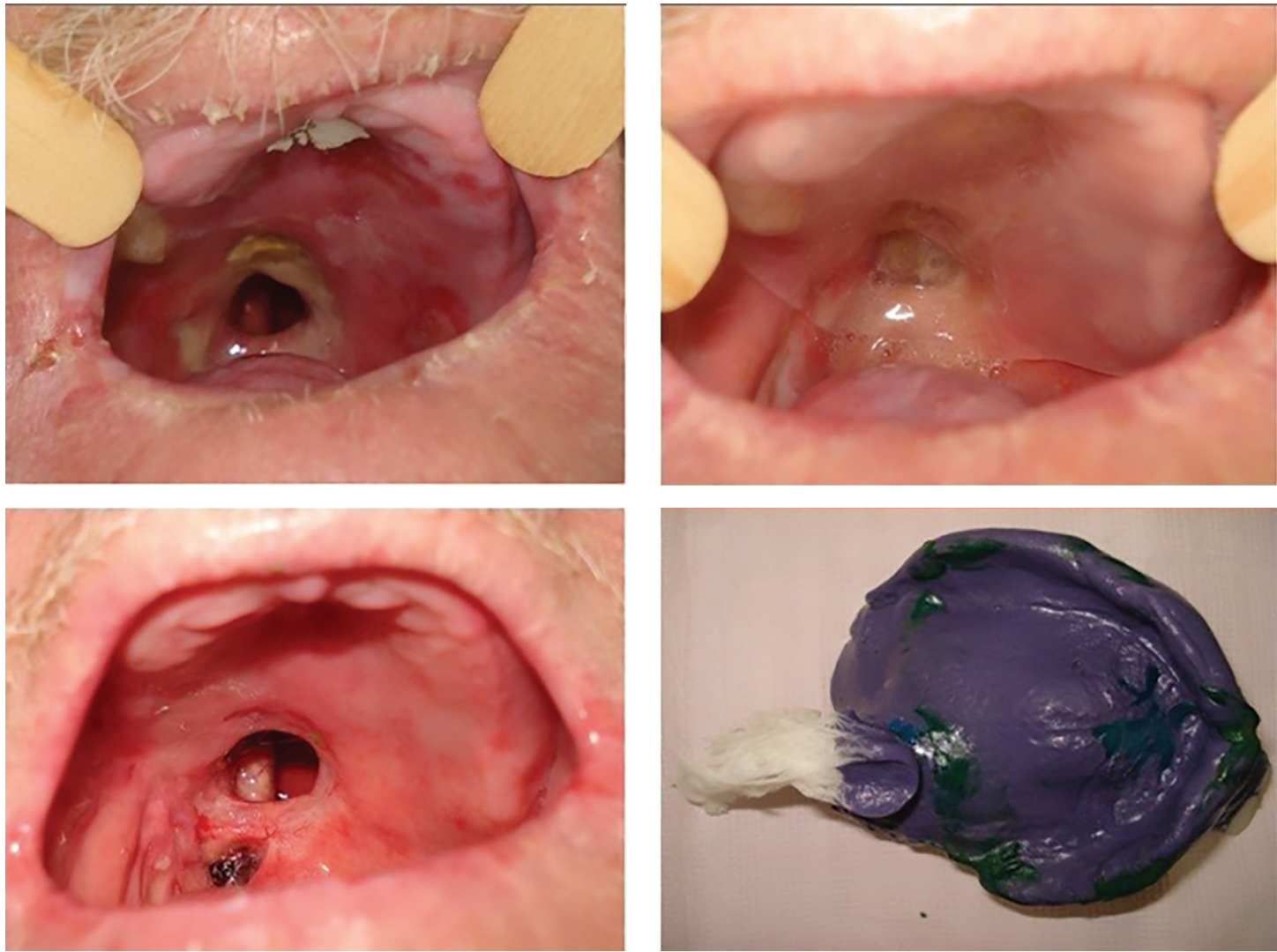

Figure 1 . A) patient initial aspect; B) Silicone obturator plate positioned in the mouth; C) Palate aspect when starting to make the obturator prosthesis; D) Functional molding with godiva and polyether.

\section{Case 3}

Female patient, 55 years old, non-smoker, nondrinker of alcoholic beverages, came to the Hospital's dentistry service still in the pre-surgery period in March 2013 with a lesion diagnosed as low-grade Polymorphous Adenocarcinoma CT2NOMx between the hard palate and the soft palate. On that occasion, an upper arch impression was performed for installing a silicone obturating plate immediately after the oncological surgery. In May 2013 the patient underwent a partial maxillectomy, which left her with trismus and an oro-nasal communication as postoperative complications (Figure 5). The patient was instructed to performing exercises to increase her mouth opening and in the first postoperative month, the definitive prosthetic procedure started with a provisional appliance, as the operated area was still healing. Only 2 clinical and 1 laboratory sessions were required; in the first clinical session, impressions were taken and in the second, the device was installed. In both steps, care regarding the communication area was observed as described in the previous cases. Two months after surgery, a new device began to be made because the oro-nasal cavity had reduced in size, yet the patient's mouth opening was still increasing. The current provisional device was relined with soft resin for a better adaptation. In December 2013, the device needed yet another adjustment and then a third provisional obturating prosthesis was made with shorter extension towards the palate and greater volume inside the cavity, which was followed by marked improvement in her speech and nasal reflux of ingested liquids. In the oncological follow-up period, the patient reported to the Head and Neck Surgeon requesting surgery to remedy the communication area, a procedure that was considered by the physician as a low probability of success. In May 2014 the patient returned with an ill-adapted prosthesis due to deformation of the metal clasps. A tooth-supported nickelchrome device was proposed (patient is fully dentate in the upper arch and needed to teeth replacement), but the patient was resistant to undergo a procedure that would require private financial investment. At this point, a new provisional prosthesis was made (Figure 6), a procedure that was repeated 1 year later when the patient declined a definitive appliance and was awaiting an evaluation by a Plastic Surgeon. 

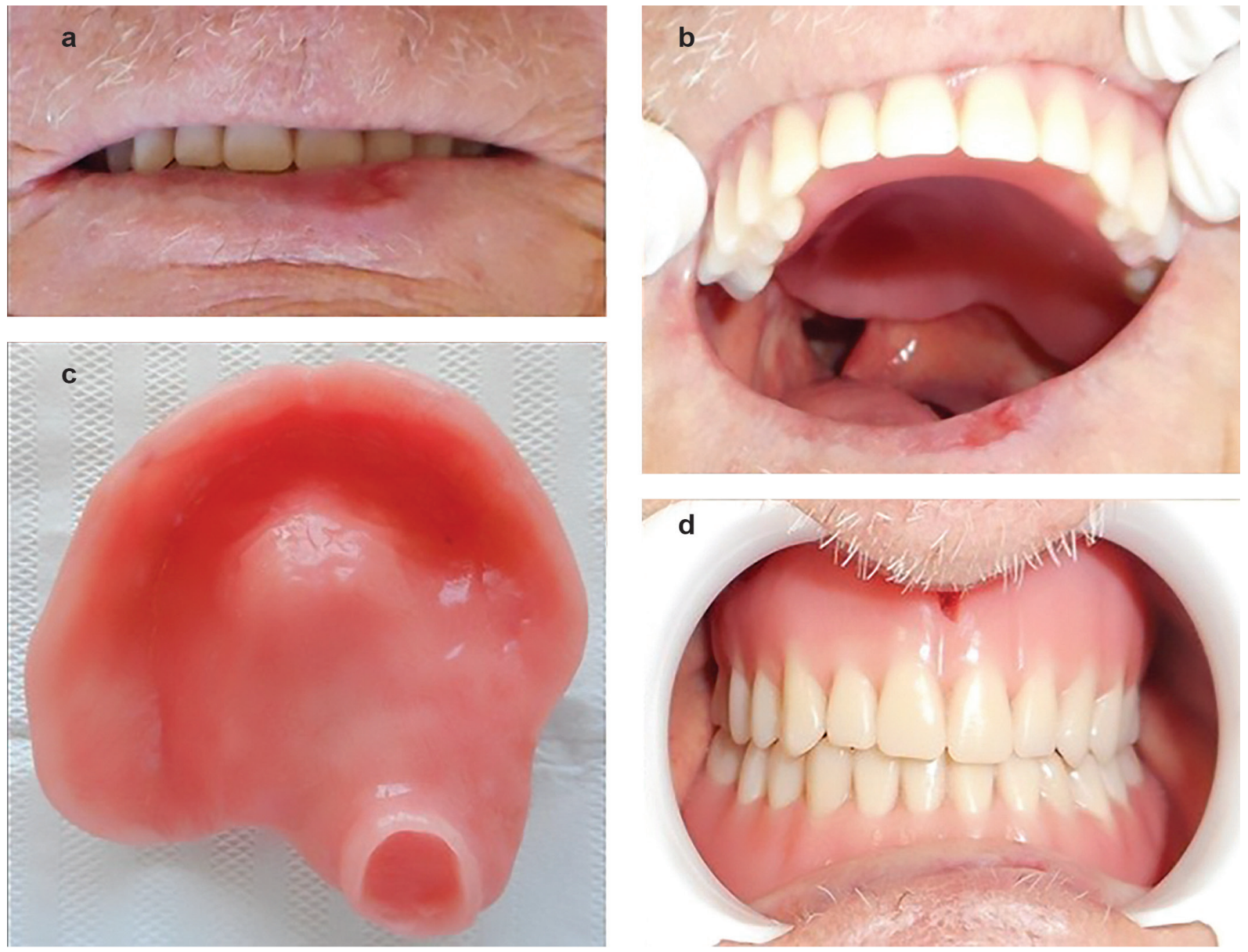

Figure 2 . Patient smiling with the obturator prosthesis in the mouth; B - D) Aspect of the total obturator prosthesis just over 2 years after its installation.

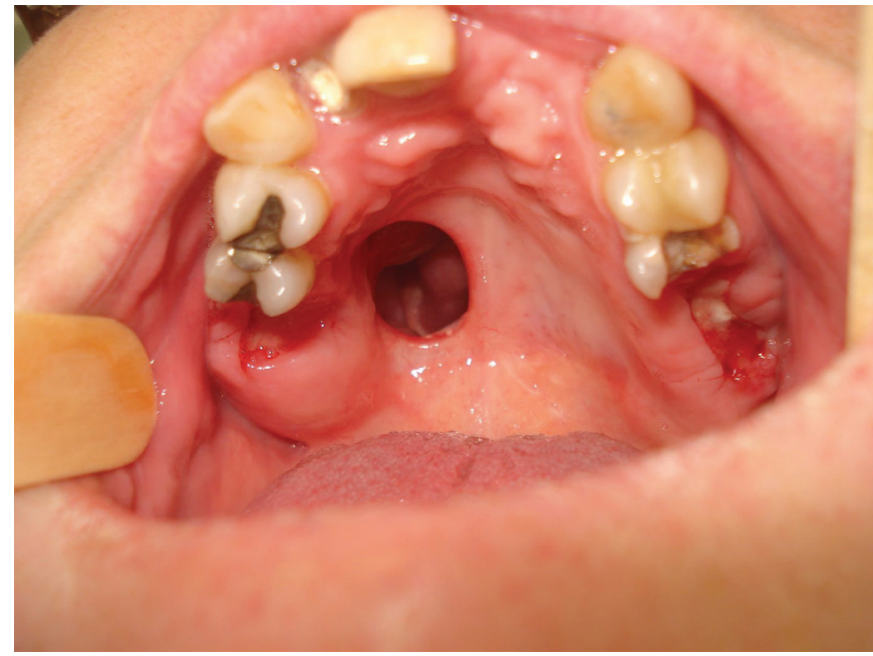

Figure 3 . Patient intraoral aspect at the dental treatment beginning.

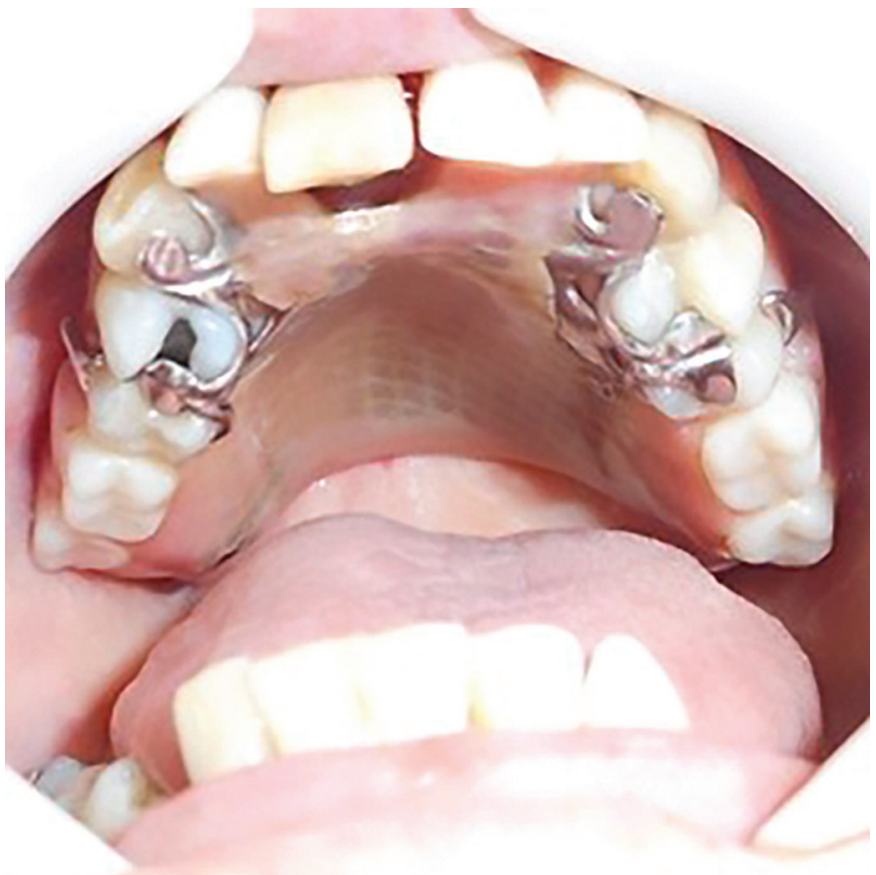

Figure 4 . Patient final aspect with the definitive obturator prosthesis in use for 3.5 years. 

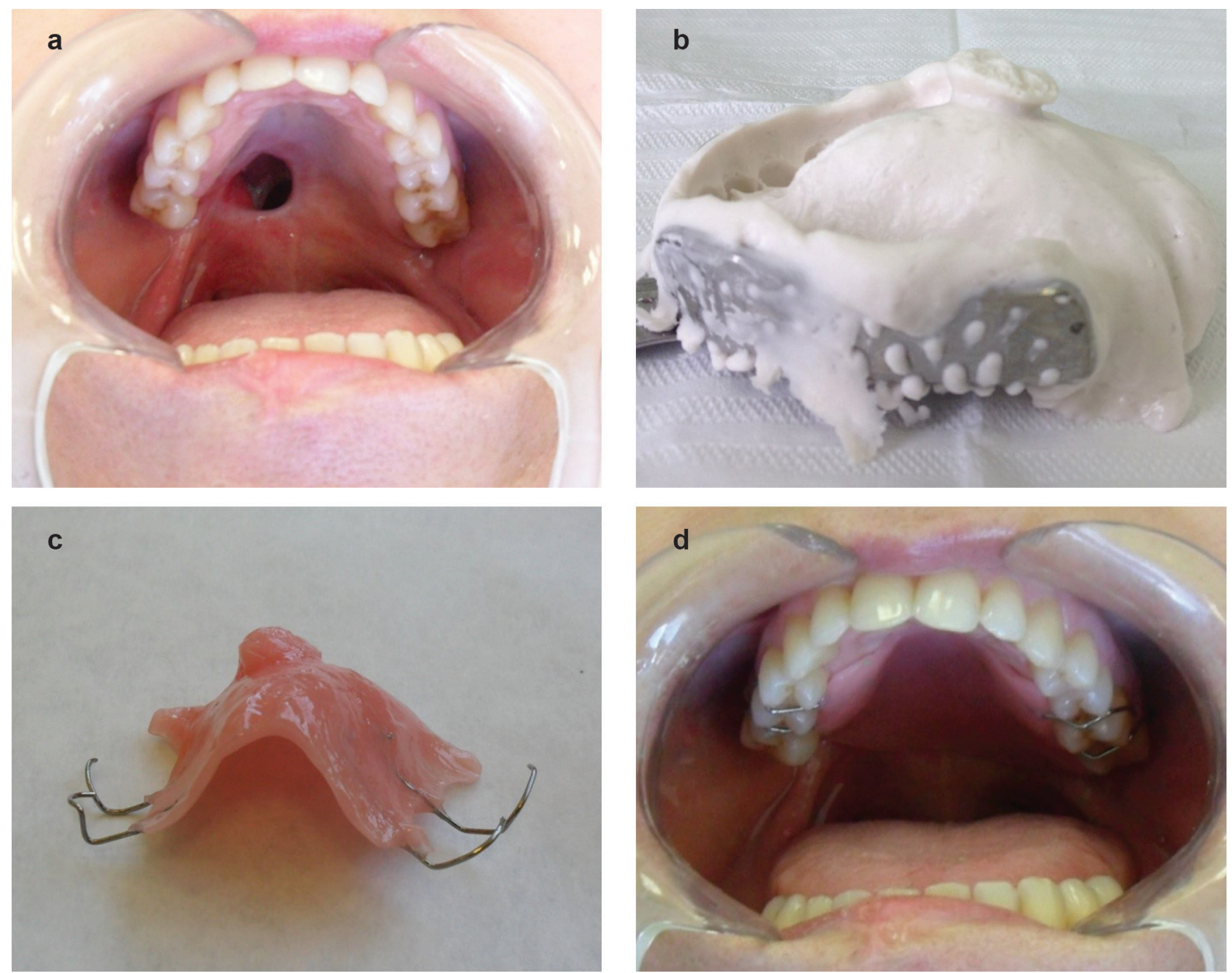

Figure 5 . A) Current aspect of the patient palate.B) Molding with alginate.C) Provisional obturator prosthesis.D) Provisional obturator prosthesis installed.

\section{DISCUSSION}

Patients with intraoral disability resulting from maxillectomy complain about swallowing difficulties and fluids reflux through the nasal cavity accompanied by speech/communication difficulties ${ }^{5-6}$, which were observed in the three cases described herein at the beginning of the treatment and noticed upon removal of the obturating prosthesis.

Several authors ${ }^{8-10}$ agree that the installation of an obturating prosthesis improves the speech intelligibility and decreases hypernasality, which was confirmed immediately after prosthesis installation in all the 3 cases described. Hattori et al. ${ }^{10}$, credit such benefits to the blocking of air passage between the oral and nasal cavities and the facilitation of pronunciation due to the presence of artificial teeth and the prosthesis base.

Although maxillectomized patient rehabilitation can be surgical or a combination of surgery and prosthesis, the prosthetic rehabilitation was the chosen treatment in the rehabilitations described herein as it facilitated cancer patients' follow-up and involved relatively low costs, achieving immediate esthetic and functional improvement ${ }^{7}$. In case 3 , the patient's difficulty in finding a Head and Neck Surgeon or a Plastic Surgeon that performed surgical reconstruction of the defective site reinforces the importance of an obturator in the rehabilitation of such individuals. 
The literature basically brings two types of materials for impressions of patients with oro-nasal/sinus communication: alginate ${ }^{2}$ and silicone-based elastomeric materials ${ }^{2,6}$. All above-reported patients were molded with alginate, due to easy handling, fast setting and relatively lower cost compared to silicone, with satisfactory results. The impression technique also reported by Singh et al. ${ }^{11}$ was used, which involved inserting a Vaseline-embedded gauze inside the cavity to prevent impression material extravasation inside the nose or the maxillary sinus. In the first case, after the initial alginate impression for study models, the functional impression was taken with polyether in order to gather more anatomical detail and improve the adaptation of the device to the surrounding tissues.

In all cases described, the obturator was part of the prosthesis and consisted of acrylic resin, the same material of the prosthetic base. Obturators separated from the prosthesis are also described in the literature? However, one must take into consideration the risk that, separated from the prosthesis, the obturator is a relatively small part that can be swallowed or aspirated.

In order to reduce the prosthesis weight, an open or closed hollow obturator can be made. Although most papers bring the closed bulb as the best option for not accumulating secretions and allowing a better hygienization, ${ }^{2,6-7}$, the open bulb was successfully used in case 1, not causing bad smell or prosthetic displacement with its use and remained celan after two years of use, thus highlighting the importance of device care by the patient, which in this case, despite the age, had no difficulties performing it. The hollowing process and removal of retentions from the obturator required no added laboratory steps or a significant increase in clinical time, since it was performed using polishing equipment by a Dental Surgeon, who noticed the overweight and retentions when receiving the appliance from the laboratory. The use of simple approaches in the creation/ adjustment of obturating prosthesis, as described above, is shown particularly important since most dental technicians do not work routinely with this type of appliance and ultimately deliver workpieces that require adjustments. In cases 2 and 3, the obturator was solid, but caused no device displacement. This can be explained on the relatively small cavities, which require less acrylic thus lower obturator weight. In case 2, there is still the advantage of the cavity being entirely in hard tissue and the support and retention being made through supports and retention clasps, which minimizes displacement of the prosthesis and improves sealing even with short vertical extensions. In case 2 , as a dentate patient, the use of clasps made with $0.7 \mathrm{~mm}$ diameter wires in the obturating prosthesis allowed an optimal retention even with the defect extending into to the soft palate region.

Despite the retention difficulties of the prosthesis inherent to patients with a palatal cavity ${ }^{2}$, rehabilitated patients rarely report this complaint. The difficulties mostly reported by patients were food reflux in the first case, which was due to the over-extension of the prosthesis basis and obturator, which was solved by polishing. Case 2, after 3.5 years of wearing the prosthesis, the patient complained of suction difficulty, but she was resistant to have the device relined in the lab using thermopolymerizable resin, as she would need to go a few days without her appliance. Direct relining with Resin Soft Comfort Macia Denso - Dencril ${ }^{\circledast}$ (the only direct relining material available at the time) was not performed due to short duration time, according to the manufacturer specifications. In case 3, the complaint was mainly the frequent deformation of the clasps made with orthodontic wires leading to instability of the prosthesis. Such difficulty could be solved using more rigid materials, but the patient declined the investment needed at that time. Still, one may consider that the rehabilitation with a provisional obturating prosthesis was quite successful in case 3 , because it allowed the patient to feed normally and communicate adequately.

From the three cases described herein, only one was referred to the Hospital's Dentistry clinic prior to surgery, which did not allow, in all cases, the application of the treatment guidelines described by Choudhury et al. ${ }^{2}$, while quoting Charlian \& Barnett, 1972 and Payne \& Welton, 1965, which suggest that prosthestic rehab planning should begin prior to surgery and a provisional device installed immediately after surgery. The same authors agree that the definitive prosthesis should be installed 3-6 months after surgery. This was not possible in the described cases, because in the first full healing of the necrotic bone tissue delayed the rehabilitation process; in the second case, the patient presented to the Dental clinic late after surgery and, in the third case, the patient refused the definitive prosthesis.

It is also relevant to reinforce the importance of dental follow-ups, which became clear in case 3, where 
reduction of the communication area occurred rapidly in the immediate postoperative period. Follow-up enabled reduction of trauma to the communication area that would occur by pressure against the healing tissues by the overextended obturator and facilitated adequate positioning of the healing tissues, preventing scarring, excessive contraction and distortion of the area, which could hinder future definitive rehabilitation².

\section{CONCLUSION}

Rehabilitation of patients with oral-nasal communication comprises the same steps as those for making conventional prostheses, which does not exclude the need to observe the individuality of each case in the

\section{REFERENCES}

1. 1. Wolff $K$, Follmann $M$, Nast $A$. The Diagnosis and Treatment of Oral Cavity Cancer. Dtsch Arztebl Int. 2006;109(48):829-35. doi: 10.3238/arztebl.2012.0829.

2. Choudhury M, Shanmuganathan N, Padmanabhan TV, Swarup S, Grover M, Arumugam M. Rehabilitation of post surgical maxillectomy defects using interim obturators-a case series. Indian J Surg Oncol. 2014;5(4):315-20. doi: 10.1007/s13193014-0361-0.

3. Murakami $M$, Nishi $Y$, Umezono $M$, Kamashita $Y$, Nishimura M. Fabrication of a movable obturator following maxillary reconstruction with slit-shaped fenestration. J Prosthodont. 2015;24(3):254-9. doi: 10.1111/jopr.12199.

4. Ishikawa S, Kikuchi N, Kobayashi T, Yamanouchi H, Tachibana H, lino M. Significant improvement in temporary dental rehabilitation by not able miniplate application in the hard palate for a patient with a large anterior maxillary defect: a case report/technique article. Head Face Med. 2013;9:34. doi: 10.1186/1746-160X-934

5. Barrios R, Montero J, González-Moles MA, Baca P, Bravo M. Level sof scientific evidence of the quality of life in patients treated for oral cancer. Med Oral Patol Oral Cir Bucal. 2013;18(4):578-84. doi:10.4317/medoral.19052

6. Krishna $\mathrm{CH}$, Babu JK, Fathima T, Reddy GV. Fabrication of a hollow bulb prosthesis for the rehabilitation of an acquired total maxillectomy defect. BMJ Case Rep. 2014;2014. doi: 10.1136/ bcr-2013-201400. planning and the need to take additional care when taking impressions and installing the appliance. Rehabilitation of such patients provides the tools with which they can resume their daily life such as talking and eating properly.

\section{Collaborators}

JM DOMINGUES made the prosthesis in cases 1 and 3 (in this, only the last), followed-up case 2 post-rehabilitation and participated in the paper writing. G CORRÊA guided the prosthesis manufacturing in case 3 and participated in the paper writing. RB FERNANDES FILHO guided the prosthesis manufacturing in clinical cases 1 and 2 and participated in the paper writing. ES HOSNI guided the research and participated in the paper writing.

7. Tirelli G, Rizzo R, Biasotto M, Lenarda RD, Argenti B, Gatto A, et al. Obturator prostheses following palatal resection clinical cases. Acta Otorhinolaryngol Ital. 2010;30(1):33-9.

8. Turkaslan S, Baycul T, Aydin MA, Ozarslan MM. Articulation performance of patients wearing obturators with different buccal extension designs. Eur J Dent. 2009;3(3):185-90.

9. Carvalho-Teles V, Pegoraro-Krook MI, Lauris JRP. Speech evaluation with and without palatal obturator in patients submitted to maxillectomy. J Appl Oral Sci. 2006;14(6):421-6. doi: 10.1590/ S1678-77572006000600007

10. Hattori M, Sumita Yl, Taniguchi H. Measurement of voice onset time in maxillectomy patients. Sci World J. 2014;2014. doi: 10.1155/2014/925707

11. Singh K, Singh SV, Mishra N, Agrawal KK. Management of maxillectomy defect with a hybrid hollow bulb obturator. BMJ Case Reports. 2013;2013. doi: 10.1136/bcr-2012-007658 